\title{
Structure elucidation and in vitro biological evaluation of sulfated exopolysaccharide from LAB Weissella paramesenteroides MN2C2
}

\author{
Mai N. Amer ${ }^{1}$, Eman W. Elgammal ${ }^{1 *}$, Nagwa A. Atwa ${ }^{1}$, Ahmed I. Eldiwany $^{1 *}$, Insaf E. Dawoud ${ }^{2}$, Ferial M. Rashad $^{2}$ \\ ${ }^{1}$ Chemistry of Natural and Microbial Products Department, National Research Center, (ID: 60014618), 33-El Bohouth st., Dokki, Giza, Egypt, P.O.12622 \\ ${ }^{2}$ Department of Microbiology, Faculty of Agriculture, Cairo University, Giza, Egypt P.O. 12613
}

\begin{tabular}{l}
\hline ARTICLE INFO \\
\hline Received on: $12 / 09 / 2020$ \\
Accepted on: 09/01/2021 \\
Available online: 05/05/2021 \\
\hline Key words: \\
Exopolysaccharides, \\
characterization, Weissella \\
paramesenteroides MN2C2, \\
medical applications.
\end{tabular}

\begin{abstract}
The introduction of new bio-product for human diseases treatment is still a great challenge in drug delivery field. This study aimed to extract, purify and characterize exopolysaccharide (EPS) from Weissella paramesenteroides MN2C2 which identified by $16 \mathrm{~S}$ rDNA under accession number of MK530206 in gene bank. The chemical and spectroscopic analysis using UV, FTIR, NMR and HPLC were applied. The results revealed that the product composed of $80 \%$ fructose, 9.3\% glucose and 5.6\% sucrose with acetyl groups. EDX analysis demonstrated that it formed of high ratios of carbon, nitrogen, oxygen, phosphorous and sulfur. The three-dimensional structure showed irregular compacted lumps with smooth surface. The anticancer activity revealed that the partially purified EPS was strong anticancer agent and highly selective against Colon Caco-2, Breast MCF-7 and Liver HepG-2 cancer cell lines compared to the crude ones. Both EPSs showed antiviral activity (99.99\%) against Coxsackie virus (CVB3). Their DPPH antioxidant activity acted in a dose dependent manner. From the obtained results it was concluded that our EPS can serve as a promising candidate for drug delivery.
\end{abstract}

\section{INTRODUCTION}

Exopolysaccharides (EPS) are natural complex polymers that may exist as a homopolysaccharide (one type of sugar) or heteropolysaccharide (many types of monosaccharides) (Linares et al., 2017). EPS can be produced from lactic acid bacteria (LAB) which are a group of bacteria found mostly in several fermented foods (Bajpai et al., 2016). LAB fermentation byproducts (EPS) were found to have multiple bioactivities and health-promoting effects such as immune-modulatory, antioxidant, antiallergenic, protection against infectious diseases, and antiobesity effects (Linares et al., 2017); thus, they have gained a great economic and therapeutic potential for application in industry, as antiinflammatory, antitumor, antioxidant, and antiviral drugs (Bajpai et al., 2016). Some LAB strains such as L. plantarum E9, L.

\section{*Corresponding Author}

Eman W. Elgammal (Email: emanelgammal50@yahoo.com), Ahmed I. Eldiwany (Email: ahmed_eldiwany @yahoo.com),

Chemistry of Natural and Microbial Products Department,

National Research Centre (ID: 6014618), 12311 Dokki, Giza, Egypt. rhamnosus, L. delbrueckii, L. bulgaricus B3 (Bajpai et al., 2016), and Weissella strains were considered as potential probiotic bacteria (Adesulu-Dahunsi et al., 2017), which benefit their hosts through the production of functional EPS (Trabelsi et al., 2009). Interestingly, the activity of EPS is closely related to its composition, as well as its physicochemical characteristics (Trabelsi et al., 2009). For example, sulfated polysaccharides are characteristic with their high potent and wide spectrum effects against many viral infections (Kim et al., 2010). There are different chemical and spectroscopic analyses that can detect EPS structure, for example, Fouriertransform infrared (FT-IR) and the more advanced techniques such as nuclear magnetic resonance (NMR), high-performance liquid chromatography (HPLC), and GC (Wu et al., 2014).Therefore, a great effort must be spent to deliver new and safe drug from EPS that can be applied in disease treatment, especially cancer therapy to overcome the rapid increase in cancer cases over the world (Osuntoki and Korie, 2010). The mechanistic studies of antitumor activity of LAB-EPS indicated that it has indirect induction of immunity and destruction of tumor cells, activates phagocytosis process, enhances the secretion of interferons, and reduces the production of anti-inflammatory factors (Pan et al., 2015). Furthermore, LAB can resist the free radicals of oxygen that 
cause the oxidative damage of cellular DNA, proteins, and lipids (Schieber and Chandel, 2014). Thus, LAB byproducts which have both antioxidant and anticancer activities can be applied as a safe and effective drug (Wang et al., 2017).

On the other hand, LAB-EPS has a significant ability against viral infections caused by respiratory, gastroenteric, murine, influenza, herpes, and Newcastle disease viruses (Kim et al., 2010). However, there were antiviral agents still not available for clinical use till now, for example, the myocarditis infectious agent called coxsackievirus (Wang et al., 2012) and recently coronavirus (Harrison, 2020). Their mode of action depended on adsorption hindrance, internalization of the virus inside the cell, production of antiviral agents, and antiviral effect through immunomodulation. Therefore, the wide spectrum of antiviral compounds can effectively and rapidly reduce viral infection rates and combat possible pandemics (Harrison, 2020).

The aim of the current study was to isolate and identify a potential LAB strain which has the ability to produce EPS with valuable properties as a future drug. The produced EPS was extracted and partially purified and its structure was determined by the chemical and spectroscopic analysis, as well as its in vitro bioactivity estimation was tested as anticancer, antiviral, and antioxidant agents.

\section{MATERIALS AND METHODS}

\section{Sampling and bacterial isolation}

Samples of colostrums were collected from four buffalos after 24-48 hours of delivery. The samples were refrigerated at $4^{\circ} \mathrm{C}$ until processed within 24 hours. Nine $\mathrm{ml}$ of $0.9 \%$ sterile saline solution was added to $1 \mathrm{ml}$ colostrum and mixed. Then, $0.1 \mathrm{ml}$ was inoculated to DeMan-Rogosa-Sharpe (MRS) agar plates and incubated anaerobically at $37^{\circ} \mathrm{C}$ for 48 hours. Then, 20 colonies were selected randomly from each sample and sub-cultured onto MRS plates for further analysis (Sepp et al., 1997).

\section{Presumptive identification of LAB}

Gram reaction and catalase production were checked for all isolates (Holt et al., 1994). A presumptive identification was carried out by using the following tests: colony morphology and pigmentation; growth at $15^{\circ} \mathrm{C}$ for 10 days and $45^{\circ} \mathrm{C}$ for 48 hours in MRS broth and salt tolerance at $4 \%, 6.5 \%$, and $8 \% \mathrm{NaCl}$ in MRS. Furthermore, gas production from glucose was carried out using MRS broth containing $0.2 \%$ of bromocresol purple dispensed into tubes containing inverted Durham tubes. Then, $1 \%$ of $10^{6} \mathrm{cfu} / \mathrm{ml}$ of each organism was added and incubated at $37^{\circ} \mathrm{C}$ then observed after 24 hours (Davis, 1955).

\section{Screening of LAB for EPS production}

The positive bacterial isolates obtained from the previous step were inoculated separately in $100 \mathrm{ml}$ of MRS broth and incubated aerobically in a static incubator at $37^{\circ} \mathrm{C}$ for 24 hours; then EPS production was tested as mentioned by Zisu and Shah (2003).

\section{Extraction and purification of EPS}

To isolate EPS from the positive strains, the supernatants were collected and neutralized to $\mathrm{pH} 6.8$, then heated at $100^{\circ} \mathrm{C}$ for 30 minutes, and recentrifuged for 20 minutes at $4{ }^{\circ} \mathrm{C}$. To precipitate EPS, an equal volume of cold absolute ethanol was added to each supernatant and stored overnight at $4^{\circ} \mathrm{C}$. The pellets were harvested by centrifugation, washed with distilled water, and dialyzed against deionized water at $4^{\circ} \mathrm{C}$ for 24 hours and then freeze-dried and the highest EPS dry weight was selected for purification. Trichloroacetic acid $10 \%$ was added to EPS to remove proteins; then the supernatant was taken and dialyzed again as mentioned above and then freeze-dried. The purified EPS was dried in an oven at $50^{\circ} \mathrm{C}$ and weighted (Zisu and Shah, 2003). Then, the most producing isolate (2C2) was used for large-scale production by inoculating 61 of MRS broth with $2 \%$ inoculum $\left(10^{8} \mathrm{cfu} / \mathrm{ml}\right)$ and the total dry weight was detected.

\section{Molecular identification by $16 \mathrm{~S}$ rDNA}

The most potent strain was identified by $16 \mathrm{~S}$ rDNA sequencing. PCR amplification was carried out using universal primers and conditions described by Sange et al. (1977). The products of PCR were purified using the QIAquick PCR purification kit according to the supplier's instructions (Qiagen, Hilden, Germany). DNA sequences were determined by the dideoxy chain termination method (Sange et al., 1977). DNA similarity was determined by the BLAST search tool within the National Centre of Biotechnology Information (NCBI) GenBank.

\section{Chemical characterization of EPS}

The partially purified EPS (30 mg) was divided into six parts; each part $(5 \mathrm{mg})$ was subjected to one analysis of the following.

\section{Ultraviolet-visible spectroscopy (UV)}

The UV spectrum analysis of EPS was determined by dissolving the sample in distilled water and then detected with a UV-visible spectrophotometer at wavelengths ranging from 190 to $800 \mathrm{~nm}$ using T80+UV/VIS Spectrometer, PG Instrument Ltd.

\section{Fourier-transform infrared (FT-IR)}

The IR spectrum analysis was carried out using FT-IR, Jasco 6100, Model Japan, Resolution: $4 \mathrm{~cm}^{-1}$. The sample was ground with spectroscopic grade potassium bromide powder and then pressed into a $1 \mathrm{~mm}$ pellet for FT-IR measurement in the frequency range of $400-4,000 \mathrm{~cm}^{-1}$.

\section{Nuclear magnetic resonance (NMR)}

The ${ }^{1} \mathrm{H}$ NMR spectra were recorded by using BRUKER 500 spectrometer. About $5 \mathrm{mg}$ of our EPS sample was dissolved in $0.75 \mathrm{ml}$ of DMSO and placed in a $5 \mathrm{~mm}$ NMR tube. The temperature of the sample was adjusted to $25^{\circ} \mathrm{C}$. The chemical shift axis was calibrated with respect to the residual solvent proton at $4.78 \mathrm{ppm}$.

\section{High-performance liquid chromatography (HPLC)}

About $5 \mathrm{mg}$ of EPS was hydrolyzed for about 4 hours; then the hydrolysate was dissolved in distilled water to be injected in HPLC (Boual et al., 2012). The analysis was carried out using Agilent Technologies 1,100 series liquid chromatograph equipped with an autosampler and a refractive 
index detector. The analytical column was a Shim-pack SCR$101 \mathrm{~N}$. The mobile phase was ultrapure water. The flow rate was kept at $0.7 \mathrm{ml} /$ minutes for a total run time of 20 minutes with isocratic elution. Each carbohydrate concentration was determined after integration of respective areas and their comparison with standard curves obtained with sucrose, glucose, and fructose (Sigma, USA).

\section{Scanning electron microscopy (SEM)}

The microstructure and surface morphology of EPS were observed using a JEOL JEM-2100 Electron Microscope at an accelerating voltage of $20 \mathrm{keV}$. The EPS was fixed in $2.5 \%$ of glutaraldehyde (Sigma) and then dehydrated by ethanol. Next, samples were covered with gold using a sputter coater (Scancoat six, Oxford) and observed under scanning electron microscope operating at $20 \mathrm{keV}$. Micrographs were recorded at higher magnification to ensure clear images (Michalak et al., 2011).

\section{Energy dispersive X-ray (SEM-EDX) and mapping analysis}

The elemental composition of the EPS was determined by EDX analyzer equipped with SEM. The X-ray spectrum of the elements was obtained at an accelerating voltage of $20 \mathrm{keV}$. The elemental analysis, as well as ions distribution (mapping) on investigated samples, was carried out using an EDX system according to Michalak et al. (2011).

\section{EPS applications}

\section{In vitro anticancer activity}

The in vitro cytotoxicity assay was assessed using five human cell lines (breast cancer cell line (MCF-7), lung cancer cell line (A549), hepatocellular carcinoma cell line (HepG2), colorectal adenocarcinoma cell line (Caco-2), and human lung normal cell line (Wi-38)]. First, the cells were inoculated in Roswell Park Memorial Institute (1640) medium in 96-well microtiter plates at a concentration of $10^{3}$ cell/well and then incubated for 24 hours at $37^{\circ} \mathrm{C}$ under $5 \% \mathrm{CO}_{2}$ incubator. After that, a fresh medium was added to the wells followed by the addition of different concentrations of our samples (0.5-25 $\mathrm{mgml}^{-1}$ ) against the negative control (cells alone); then the plates were incubated for further 48 hours. Forty $\mu \mathrm{l}$ of $2.5 \mu \mathrm{g} \mathrm{ml} \mathrm{l}^{-1}$ (3-(4, 5-dimethylthiazol-2-yl)-2,5-diphenly tetrazolium bromide) was added to each well and incubated for 4 hours at $37^{\circ} \mathrm{C}$. To stop the reaction, $200 \mu \mathrm{l}$ of $10 \%$ sodium dodecyl sulfate was added to each well and incubated overnight. The positive control was prepared using the cytotoxic doxorubicin standard $\left(50 \mu \mathrm{g} \mathrm{ml}^{-1}\right)$ to give $100 \%$ lethality under the same conditions (Thabrew et al., 1997). Then, the absorbance was measured at $540 \mathrm{~nm}$ using a microplate multi-well reader.

Viability $\%=($ Reading of extract/Reading of negative control -1$) \times 100$.

\section{Selectivity index (SI)}

The degree of selectivity of the compounds was expressed by its SI value. A high SI value $(>2)$ indicates selective toxicity to cancer cells, while a low SI value $(<2)$ is known to induce cytotoxicity in normal cells (Awang et al., 2014). SI value $=\mathrm{IC}_{50}$ normal cell/ $/ \mathrm{IC}_{50}$ cancer cell.
Antiviral activity by measuring of cytopathic effect

A safe dilution from EPS samples was prepared to be evaluated against coxsackievirus type B3 (CVB3) infection. Activated CVB3 was diluted in culture medium in a range of $10^{-4}-10^{-7}$; then $50 \mu \mathrm{l}$ from each dilution was incubated with an equal volume of EPS at $37^{\circ} \mathrm{C}$ for 1 hour in microtiter plate using $\mathrm{CO}_{2}$ incubator against control (without EPS). The EPS samples were used at concentrations of 1.5 and $3 \mathrm{mg} / \mathrm{ml}$. Then, a fresh medium was added to the treated and untreated virus and then the plates were incubated at $37^{\circ} \mathrm{C}$ in $\mathrm{CO}_{2}$ incubator for 72 hours. The cytopathic effect was observed under an inverted microscope and virus titration was calculated as $50 \%$ tissue culture infection dose $\left(\right.$ TCID $\left._{50}\right)$ as described by Shaheen et al. (2015). Differences between the values of treated and untreated virus gave the reduction in virus titer.

Antioxidant activity with 2,2-Diphenyl-1-picrylhydrazyl (DPPH) radical-scavenging assay

DPPH method was applied to detect the free radicalscavenging activity of our EPS samples (Yin et al., 2010). Different concentrations $(40,80,120,160,200$, and $240 \mu \mathrm{g} / \mathrm{ml})$ of crude and partially purified EPS samples were prepared in methanol, and then $100 \mu \mathrm{l}$ was mixed with $900 \mu \mathrm{l}$ of DPPH shaken vigorously and incubated in the dark for 30 minutes. The decrease in absorbance was measured at $517 \mathrm{~nm}$ against control.

$\%$ Free radical scavenging $=[(\mathrm{A}$ control $-\mathrm{A}$ sample $) / \mathrm{A}$ control] $\times 100$,

where A sample is the absorbance of DPPH solution with sample and A control is the absorbance of DPPH solution in methanol without sample.

\section{Statistical analysis}

All of the determinations reported in this study were carried out in triplicate, and the results are presented as mean values.

\section{RESULTS AND DISCUSSION}

\section{Screening, biochemical, and physiological identification of LAB}

Eighty different isolates were isolated from four buffalo colostrum samples; only 53 were presumptively assigned to Lactobacillus genus (Collins et al., 1993). All our lactobacilli formed white, cocci colonies with concave apex and regular margin. They were Gram-positive and catalase-negative. The isolates grew well at $15^{\circ} \mathrm{C}$ and $45^{\circ} \mathrm{C}$; also they showed growth in MRS broth medium containing $2 \%-8 \% \mathrm{NaCl}$ indicating that they are salt-tolerant. Most of them can produce gas from glucose indicating that they are heterofermentative type which can ferment sugars to produce different products including gases (Table 1). This is in accordance with Mulaw et al.'s (2019) study who obtained the same results with homo- and heterofermentative LAB.

\section{Selection of high EPS-producing strain for large-scale production}

The most potent isolate was strain number $2 \mathrm{C} 2$ (Weissella paramesenteroides) which gave the highest amount 
Table 1. Identification of LAB and screening for EPS production.

\begin{tabular}{|c|c|c|c|c|c|c|c|}
\hline \multirow{2}{*}{ Isolates no. } & \multirow{2}{*}{ Gas from glucose } & \multicolumn{2}{|c|}{ Growth at } & \multicolumn{3}{|c|}{ Growth at $\mathrm{NaCl}(w / v)$} & \multirow[t]{2}{*}{ EPS g/100 m } \\
\hline & & $15^{\circ} \mathrm{C}$ & $45^{\circ} \mathrm{C}$ & $2 \%$ & $6.5 \%$ & $8 \%$ & \\
\hline c1 & + & + & + & + & + & + & 0.00 \\
\hline c15 & + & + & + & + & + & + & 0.00 \\
\hline c16 & + & + & + & + & + & + & 0.00 \\
\hline c17 & + & + & + & + & + & + & +0.12 \\
\hline c18 & + & + & + & + & + & + & +0.12 \\
\hline c19 & + & + & + & + & + & + & 0.00 \\
\hline c20 & + & + & + & + & + & + & 0.00 \\
\hline $2 \mathrm{c} 1$ & + & + & + & + & + & + & 0.00 \\
\hline $2 \mathrm{C} 2$ & + & + & + & + & + & + & +0.38 \\
\hline $2 \mathrm{c} 8$ & + & + & + & + & + & + & 0.00 \\
\hline $2 \mathrm{c} 9$ & + & + & + & + & + & + & +0.15 \\
\hline $2 \mathrm{c} 10$ & + & + & + & + & + & + & 0.00 \\
\hline $2 \mathrm{c} 11$ & - & + & - & + & + & - & 0.00 \\
\hline $2 \mathrm{c} 12$ & + & + & + & + & + & + & +0.13 \\
\hline $2 \mathrm{c} 14$ & + & + & + & + & + & + & +0.14 \\
\hline $2 \mathrm{c} 15$ & + & + & + & + & + & + & +0.13 \\
\hline $2 \mathrm{c} 16$ & + & + & - & + & + & - & 0.00 \\
\hline $3 \mathrm{c} 1$ & + & + & + & + & + & + & 0.00 \\
\hline $3 \mathrm{c} 2$ & + & + & + & + & + & + & 0.00 \\
\hline $3 \mathrm{c} 3$ & + & + & + & + & + & + & 0.00 \\
\hline $3 c 4$ & + & + & + & + & + & + & 0.00 \\
\hline $3 c 5$ & - & + & + & + & + & + & 0.00 \\
\hline $3 \mathrm{c} 6$ & + & + & + & + & + & + & 0.00 \\
\hline $3 c 7$ & + & + & + & + & + & + & +0.14 \\
\hline $3 \mathrm{c} 8$ & + & + & + & + & + & + & +0.15 \\
\hline $3 \mathrm{c} 9$ & + & + & + & + & + & + & +0.13 \\
\hline $3 \mathrm{c} 10$ & + & + & + & + & + & + & 0.00 \\
\hline $3 \mathrm{c} 11$ & + & + & + & + & + & + & 0.00 \\
\hline $3 \mathrm{c} 12$ & + & + & + & + & + & + & 0.00 \\
\hline $3 \mathrm{c} 13$ & + & + & + & + & + & + & 0.00 \\
\hline $3 \mathrm{c} 14$ & + & + & + & + & + & + & 0.00 \\
\hline $3 \mathrm{c} 15$ & + & + & + & + & + & + & 0.00 \\
\hline $3 \mathrm{c} 16$ & + & + & + & + & + & + & 0.00 \\
\hline $3 \mathrm{c} 20$ & + & + & + & + & + & + & 0.00 \\
\hline $4 \mathrm{c} 1$ & + & + & + & + & + & + & 0.00 \\
\hline $4 \mathrm{c} 2$ & + & + & + & + & + & + & 0.00 \\
\hline $4 c 3$ & + & + & + & + & + & + & 0.00 \\
\hline $4 \mathrm{c} 4$ & + & + & + & + & + & + & +0.12 \\
\hline $4 c 5$ & + & + & + & + & + & + & 0.00 \\
\hline $4 \mathrm{c} 6$ & + & + & + & + & + & + & 0.00 \\
\hline $4 c 7$ & + & + & - & + & + & + & +0.17 \\
\hline $4 \mathrm{c} 9$ & + & + & + & + & + & + & 0.00 \\
\hline $4 \mathrm{c} 10$ & + & + & + & + & + & + & +0.19 \\
\hline $4 \mathrm{c} 11$ & - & + & - & + & + & - & 0.00 \\
\hline $4 \mathrm{c} 12$ & - & + & + & + & + & + & 0.00 \\
\hline $4 \mathrm{c} 13$ & - & + & + & + & + & + & +0.18 \\
\hline $4 \mathrm{c} 14$ & - & + & + & + & + & + & +0.15 \\
\hline $4 \mathrm{c} 15$ & - & + & + & + & + & + & +0.17 \\
\hline $4 \mathrm{c} 16$ & - & + & - & + & + & - & 0.00 \\
\hline $4 \mathrm{c} 17$ & - & + & - & + & + & + & 0.00 \\
\hline $4 \mathrm{c} 18$ & - & + & + & + & + & + & 0.00 \\
\hline $4 \mathrm{c} 19$ & - & + & + & + & + & + & 0.00 \\
\hline $4 \mathrm{c} 20$ & - & + & + & - & + & - & 0.00 \\
\hline
\end{tabular}




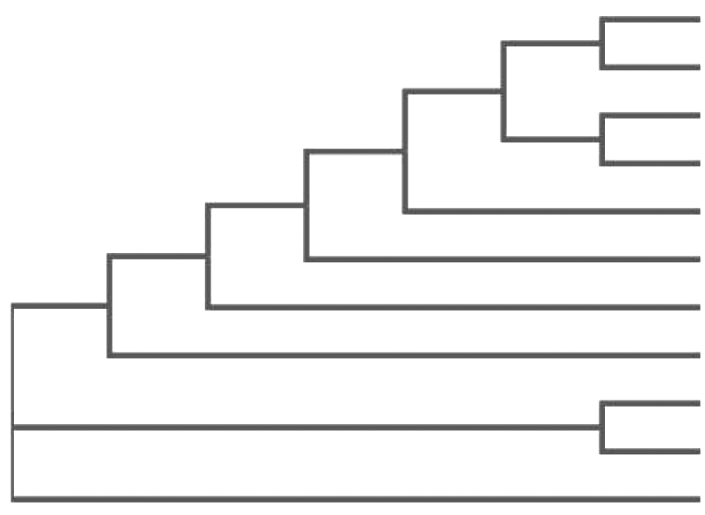

NR 113338.1 Lactobacillus plantarum NBRC 15891

NR_113334.1 Lactobacillus curvatus NBRC 15884

NR_074957.1 Leuconostoc mesenteroides ATCC 8293

NR_109003.1 Leuconostoc suionicum LMG 8159

MK530206.1 Weissella paramesenteroides MN 2c2

NR_114312.1 Weissella oryzae SG25

NR_040813.1 Weissella viridescens NRIC 1536

NR_113775.1 Weissella hellenica NBRC 15553

MK530237.1 Weissella confusa strain G C NR_104568.1 Weissella paramesenteroides NRIC 1542 AB775181.1 Weissella paramesenteroides strain: 606

Figure 1. Phylogenetic tree of Weissella paramesenteroides MN2C2.

of EPS $>0.3 \mathrm{~g} \%$ (Table 1). This strain was used for the largescale production of crude EPS. Also, Jin et al. (2019) found that Weissella confusa VP30 strain produced the highest amount of EPS compared to other LAB strains which produced $<0.3 \mathrm{~g} \%$ of EPS on MRS broth.

\section{Molecular identification the most potent isolate by 16S rDNA}

$16 \mathrm{~S}$ rDNA sequencing was applied to get accurate identification of the rare bacterial strain. A partial 420 bp linear DNA sequence for isolate number $\mathrm{MN} 2 \mathrm{C} 2$ has been aligned and clustered with NCBI database sequences. The phylogenetic tree (Fig. 1) and the analysis of the 16S rDNA gene sequence revealed that this strain clearly belongs to the 16Sr DNA strain Weissella paramesenteroides NRIC with $99 \%$ similarity. The locus sequences of DNA linear were deposited in the gene bank under the accession number of MK530206.

\section{EPS characterization}

\section{Spectroscopic analysis}

\section{UV-visible absorption spectrum}

This analysis can be applied to detect chromophore groups of atoms characterized by strongly absorbing electronic transitions of the purified EPS. Figure 2a shows the presence of two peaks in the UV area. The first peak at $192 \mathrm{~nm}$ had $\pi-\pi^{*}$ transitions, which is related to many functional groups such as ester, carbonyl, and carboxyl or amine. A small peak (256 nm) found in the area from $250 \sim 280 \mathrm{~nm} \pi-\pi^{*}$ electronic transition is indicative of aromatic and polyaromatic compounds including protein and/or nucleic acid (Trabelsi et al., 2009).

\section{FT-IR analysis}

The FT-IR analysis is a powerful tool for the identification of the functional groups of polymers, organic compounds, and many other compounds (Liu et al., 2017). Figure 2b shows FTIR spectrum of our polysaccharide in the range of 4,000-400 $\mathrm{cm}^{-1}$. The broadband at $3,438 \mathrm{~cm}^{-1}$ is assigned to $-\mathrm{OH}$ group which is characteristic of polysaccharides, indicating the presence of a carbohydrate ring. The absorption bands at 2,929 $\mathrm{cm}^{-1}$ are attributed to $\mathrm{C}-\mathrm{H}$ asymmetric stretching of methyl or methylene groups that almost found in hexoses (Kumar et al., 2011). The stretching vibration of $\mathrm{C}=\mathrm{O}$ bond is observed at the region 1,637 $\mathrm{cm}^{-1}$, while the regions of 1,444 and 1,297 could be indicated for the presence of C-O that present in ether or alcohol groups (Liu et al., 2017). The specific fingerprint region that identifies any EPS found between 950 and $1,200 \mathrm{~cm}^{-1}$ regions mostly represents pyranose ring vibrations overlapped with stretching vibrations mainly attributed to $\mathrm{C}-\mathrm{O}-\mathrm{C}$ glycosidic bond and $\mathrm{C}-\mathrm{O}-\mathrm{H}$ side groups (Dubey and Jeevaratnam, 2015). There was no absorption band in the region of $1,700-1,770 \mathrm{~cm}^{-1}$ indicating the absence of glucuronic acid and diacetyl ester (Wang et al., 2015). This is in agreement with Kanamarlapudi and Muddada (2017) who obtained the same results with EPS from probiotic Streptococcus thermophilus.

\section{NMR analysis}

This method has been used to determine sugar units indicated by the chemical shifts (ppm) (Fig. 2c). Generally, the ${ }^{1} \mathrm{H}$ NMR polysaccharide spectrum consists mainly of three regions. The first one is formed of overlapping nonanomeric skeletal proton signals present between $\delta \mathrm{H} 3.3$ and 4 ppm and it is characteristic for the ring proton region of several sugar residues of the polysaccharides (Ismail and Nampoothiri, 2010). The second region is called the anomeric proton region $(\delta \mathrm{H} 4.5-5.5$ ppm) which indicates the presence of $\alpha$ - and/or $\beta$-anomers and the type of linkage is mostly $1 \rightarrow 3,1 \rightarrow 4$, or $1 \rightarrow 6$, where our regions between $4.9-5.2 \mathrm{ppm}$ and $4.4-4.8 \mathrm{ppm}$ are due to the $\alpha$-anomeric proton and $\beta$-anomeric protons, respectively (Dubey and Jeevaratnam, 2015). Finally, the high-field reporter region between 1.2 and $2.3 \mathrm{ppm}$ showed the alkyl proton region of the third group which probably contains acetyl, acyl, or alkyl groups from glucosamine (Ismail and Nampoothiri, 2010). This result confirmed that the present product is a polysaccharide formed of $\alpha$ - and $\beta$-anomers of various hexoses and contained acetyl groups from glucosamine also; it had a pyranose ring overlapped with some side groups. This is in agreement with Jin et al. (2019) who isolated EPS from $W$. confusa VP30 and obtained the same peaks using one proton NMR.

\section{High-performance liquid chromatography (HPLC)}

HPLC technique was applied to separate and identify the detailed structure of our EPS. The refractive index chromatogram of EPS after the partial hydrolysis showed that there were three distinct peaks at the same retention times of the standard sugars 

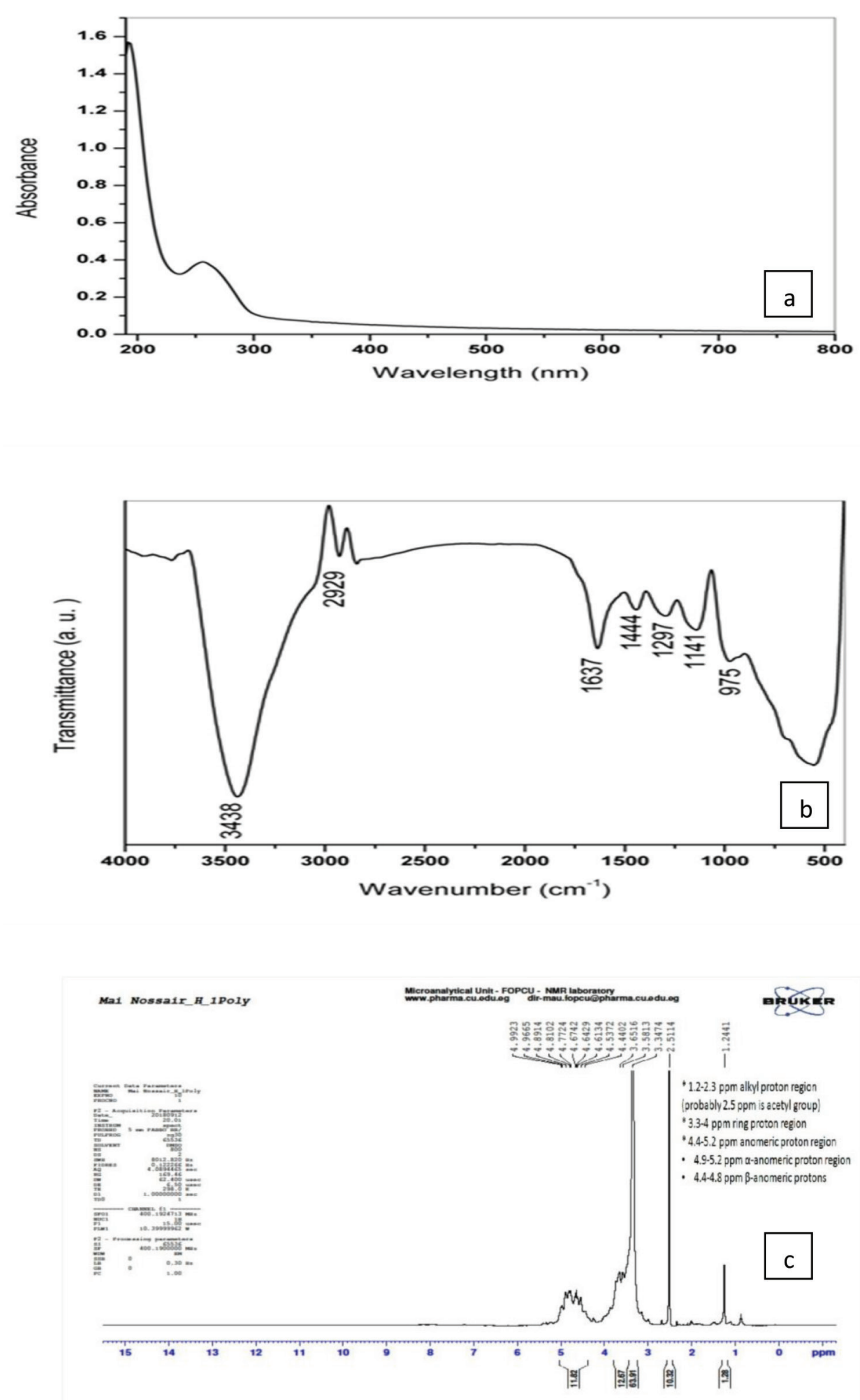

Figure 2. (a) UV-Vis spectrum; (b) FT-IR spectrum; (c) NMR spectrum of EPS.

(sucrose at 6.59 minutes, glucose at 7.96 minutes, and fructose at 8.85 minutes), in addition to the first elution peak at 5.01 minutes (Fig. 3). The highest concentration of our polysaccharide was fructose $\left(259.1 \mathrm{mg} \mathrm{ml}^{-1}\right)$ recording about $80 \%$ of total polysaccharide, followed by $9.3 \%$ glucose $\left(30.1 \mathrm{mg} \mathrm{ml}^{-1}\right)$ and $5.6 \%$ sucrose $\left(18.1 \mathrm{mg} \mathrm{ml}^{-1}\right)$. Also, there were only $5.1 \%$ of unidentified peaks $\left(12.7 \mathrm{mg} \mathrm{ml}^{-1}\right)$. In fact, the environmental and cultural conditions in addition to the strain type have a great influence on the type of the produced EPS and its monosaccharides ratios (Tukenmez et al., 2019). The same sugar content as ours was extracted from the fermented beverage of the red seaweed Gracilaria fisheri by Hayisama-ae et al. (2014). Furthermore, Ren et al. (2015) used HPLC successfully to separate mixtures of ten monosaccharides produced from Pleurotus abalonus and identified them as $87.9 \%$ d-glucose, $1.1 \%$ d-ribose, $4.4 \%$ d-galactose, $3.4 \%$ d-mannose, $1.9 \%$ l-rhamnose, and 1.4\% d-glucuronic acid. Also, Jin et al. (2019) isolated and identified EPS from $W$. confusa VP30 which consists of dextran with glucose units. The EPS structure and monomer composition are very important because

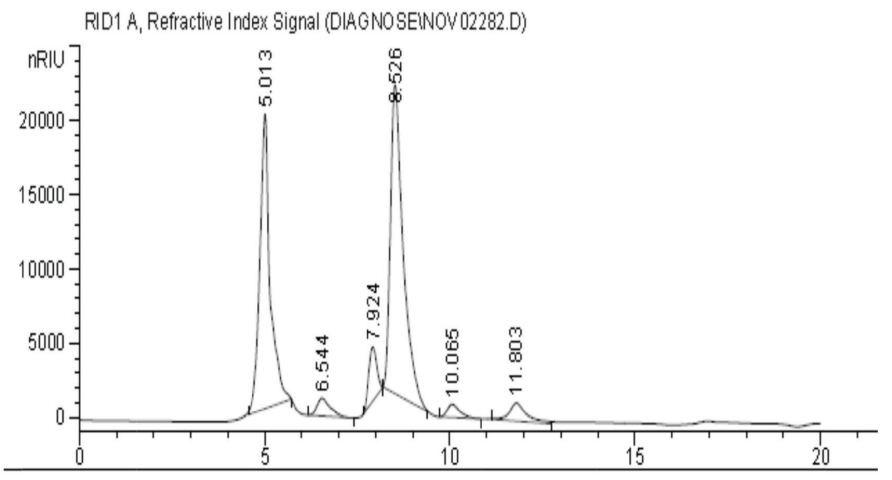

Figure 3. Chromatogram of the hydrolyzed EPS sample.

its application is dependent on its structure and it is specific for each strain (Tukenmez et al., 2019).

\section{SEM of EPS}

Generally, it was noted that different polysaccharides possessed different morphology and topography and this may be due to the difference in sample extraction, preparation, and purification. Also, it depends on the physicochemical characters of each EPS (Kanamarlapudi and Muddada, 2017). The scanning electron micrographs of our EPS are presented in Figure 4. Our EPS showed a three-dimensional structure of irregular highly compacted lumps with different sizes and a smooth surface (Liu et al., 2017). The highly compacted structures with flake-like units of EPS extracted from Lactobacillus fermentum CFR2195 were observed by Yadav et al. (2011). Also, the porous web-like and irregular structure of the EPS produced from Lactobacillus plantarum was noted by Wang et al. (2015).

\section{EDX and mapping analyses}

The EPS composed of some elements such as carbon, nitrogen, oxygen, phosphorous, and sulfur in high ratios of its weight which reached $42.31 \%, 10.11 \%, 42.68 \%, 4.13 \%$, and $0.78 \%$, respectively (Table 2 and Fig. 5a). Kanamarlapudi and Muddada (2017) obtained similar results with EPS from Streptococcus thermophiles which contains carbon, oxygen, nitrogen, and chlorine in ratios approximately near from ours. Also, our results were in harmony with Boukhelata et al. (2019) who detected the presence of carbon and oxygen as major components of EPS. This result was confirmed by mapping analysis of EPS as indicated in Figure $5 b$, where the mapping photo shows the presence of the same elements with their ratios which are only included in the selected field/area of the taken photo. Interestingly, the elemental composition and the percentage diversity were found to affect the structure and function of any EPS (Nwodo et al., 2012).

\section{In vitro biological evaluation of EPS}

\section{Anticancer activity}

Different concentrations $(0.5-25 \mathrm{mg} / \mathrm{ml})$ of both EPS from $W$. paramesenteroides $\mathrm{MN} 2 \mathrm{C} 2$ were applied and exhibited different anticancer activities against five human cell lines, namely, breast cancer cell line (MCF-7), colorectal adenocarcinoma cell line (Caco-2), hepatocellular carcinoma cell line (HepG-2), lung 

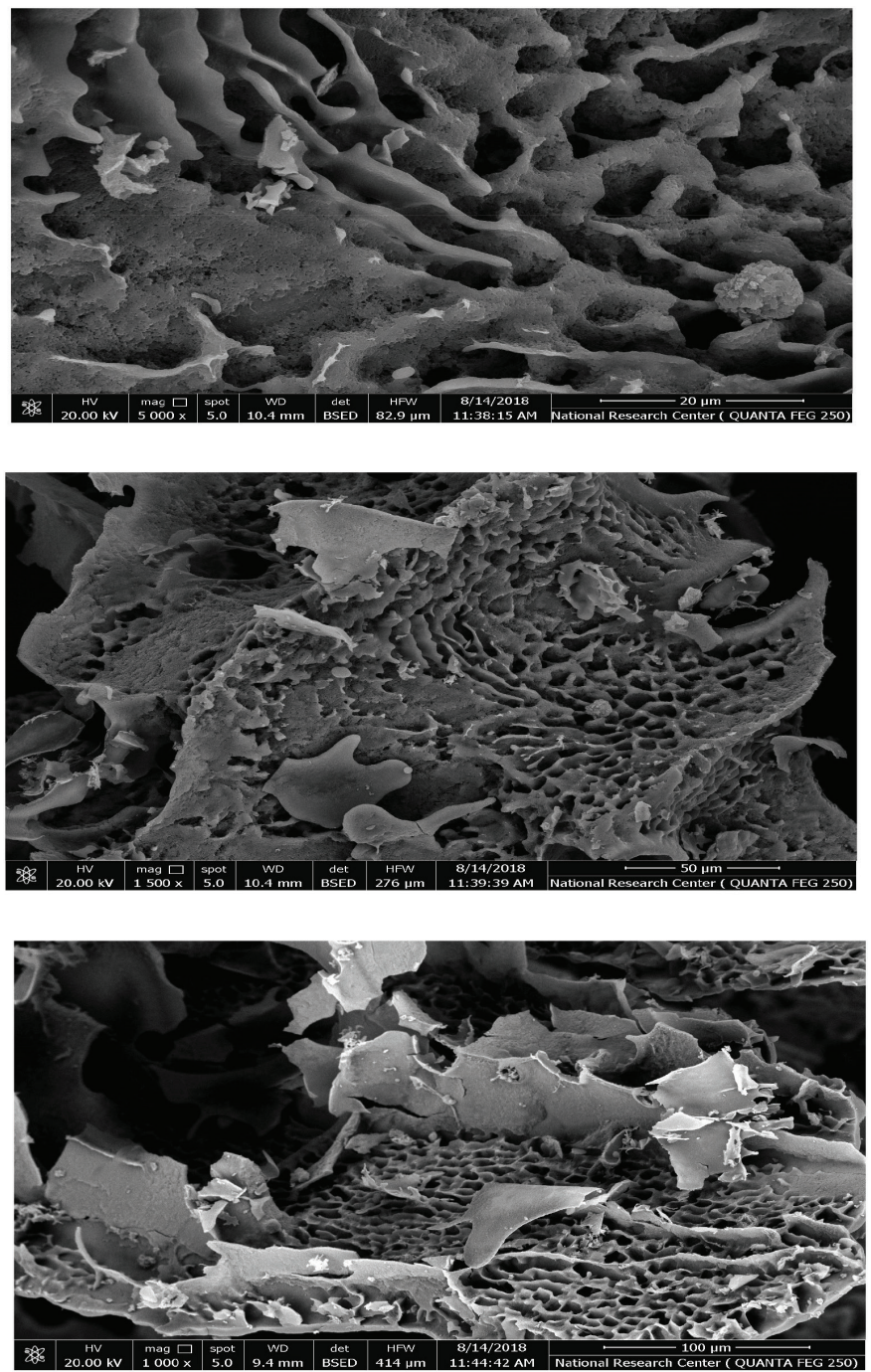

Figure 4. SEM analysis of EPS.

Table 2. EDX analysis of EPS.

\begin{tabular}{ccccc}
\hline Element & Weight \% & Atomic \% & Net int. & Error \% \\
\hline C K & 42.31 & 49.83 & 112.89 & 8.83 \\
N K & 10.11 & 10.21 & 8.22 & 21.4 \\
O K & 42.68 & 37.73 & 108.08 & 11.43 \\
P K & 4.13 & 1.89 & 72.19 & 6.39 \\
S K & 0.78 & 0.34 & 13.83 & 18.96 \\
\hline
\end{tabular}

cancer cell line (A549), and human lung normal cell line (Wi-38) (Table 3). The $\mathrm{IC}_{50}$ values of crude EPS were 4.2 for Caco-2, 7.2 for $\mathrm{MCF}-7$, and $9.1 \mathrm{mg} / \mathrm{ml}$ for Wi-38, while $\mathrm{IC}_{50}$ values of the partially purified EPS were 3.5, 2.6, 4.8, 16.5, and 26.1 for Caco2, HepG-2, MCF-7, A549, and Wi-38, respectively. HepG-2 and Caco-2 were the most sensitive cell lines, while A549 and Wi38 were the most tolerant ones to our EPS. In this line, Haroun et al. (2013) obtained $\mathrm{IC}_{50}$ values which reached 9.07, 15.8, 17.6, 19.9, 24.2, and 34.7 for CACO (intestinal carcinoma), HELA (cervical carcinoma), HCT116 (colon carcinoma), HEPG2 (liver
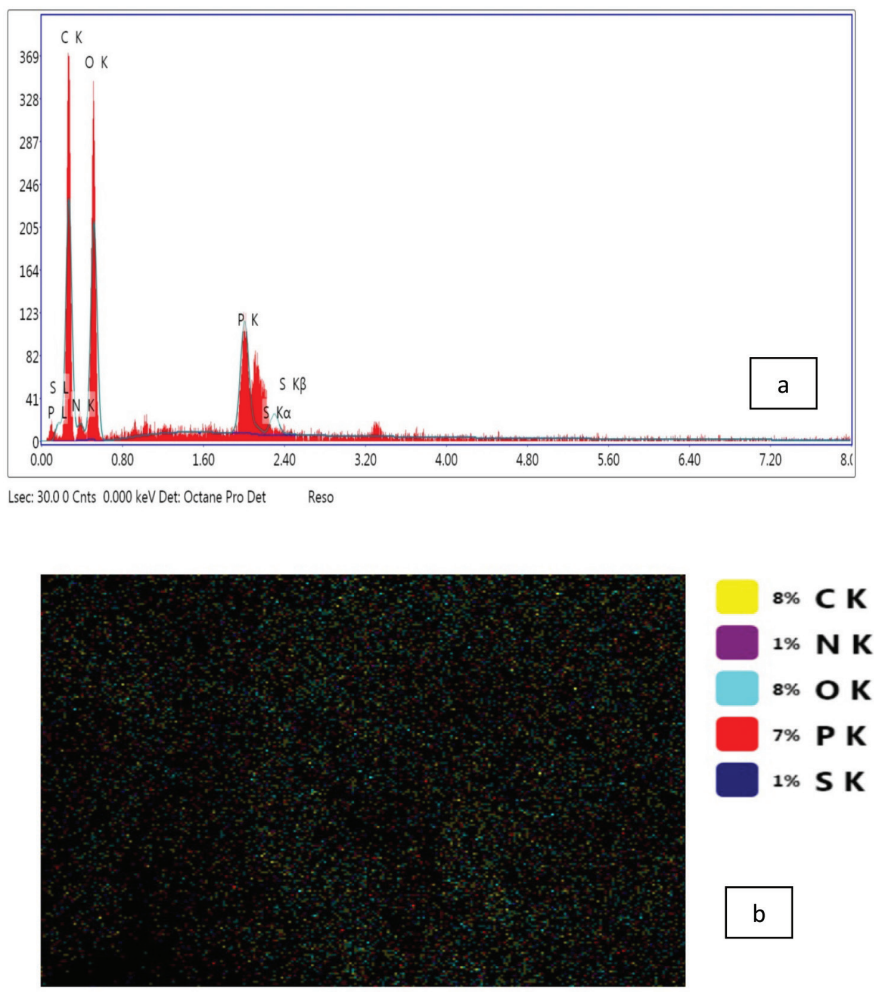

Figure 5. (a) EDX and (b) mapping analyses of EPS.

Table 3. Anticancer potential of crude and partially purified EPS.

\begin{tabular}{ccccc}
\hline \multirow{2}{*}{ Cell lines } & \multicolumn{2}{c}{ Crude EPS } & \multicolumn{2}{c}{ Pure EPS } \\
\cline { 2 - 5 } & IC $_{\mathbf{5 0}} \mathbf{~ m g} / \mathbf{m l}$ & (SI) & IC $_{\mathbf{5 0}} \mathbf{~ m g} / \mathbf{m l}$ & (SI) \\
\hline Caco-2 & 4.20 & 2.15 & 3.50 & 7.46 \\
HepG-2 & 0.00 & 0.00 & 2.60 & 9.99 \\
MCF-7 & 7.20 & 1.27 & 4.80 & 5.39 \\
A549 & 0.00 & 0.00 & 16.50 & 1.58 \\
Wi-38 & 9.10 & 1.00 & 26.10 & 1.00 \\
\hline
\end{tabular}

$\mathrm{TCID}_{50}$ and selectivity index (SI).

carcinoma), MCF7 (breast carcinoma), HEP2 (larynx carcinoma), and HFB4 (normal melanocytes) cell lines, respectively, revealing that CACO was the most sensitive one to their EPS. Furthermore, our study demonstrated that the partially purified EPS was highly selective $(\mathrm{SI}>2)$ against cancer cell lines suggesting that it had a great safety for the normal cells and this appeared especially for Caco-2, HepG-2, and MCF-7 (Haroun et al., 2013).

The mode of action of EPS is not clear until now, and it may be attributed to the induction of apoptosis of many kinds of cancer cell lines and this could be associated with the main monomer structure of each EPS (Tukenmez et al., 2019). Moreover, Zhou et al. (2019) stated that the antitumor activity is induced not only by an indirect effect of regulation of host immunity but also by a direct killing effect on cancer cells. Thus, the probiotic metabolites including polysaccharides, short-chain fatty acids, and protein inhibitory compounds can be used as alternative biotherapeutic cancer drugs (Bedada et al., 2020). 
Table 4. Antiviral activity of crude and partially purified EPS against CVB3.

\begin{tabular}{cccccc}
\hline Sample & Conc. $(\mathbf{m g} / \mathbf{m l})$ & Virus titers alone & Virus titers with EPS & Reduction value & Inhibition \% \\
\hline \multirow{2}{*}{ Crude EPS } & 3.0 & $10^{6}$ & $10^{2}$ & $10^{4}$ & 99.99 \\
& 1.5 & $10^{6}$ & $10^{2}$ & $10^{4}$ & 99.99 \\
\multirow{3}{*}{ Pure EPS } & 3.0 & $10^{6}$ & $10^{2.5}$ & $10^{3.5}$ & 99.95 \\
& 1.5 & $10^{6}$ & $10^{3}$ & $10^{3}$ & 99.90 \\
\hline
\end{tabular}

Reduction of virus titer was calculated as "virus titer without extract-virus titer with extract."

\section{Antiviral activity of EPS}

To reduce or inhibit the viral reproduction without adverse effect on host cell viability, a low toxicity medicine with broad-spectrum activity was recommended (Harrison, 2020). The antiviral activity of crude and partially purified EPS was detected against CVB3 (Table 4). Both crude and partially purified EPS have potent antiviral activity which reached 3-4 logs reduction in virus titers with lethal percentage ranged from $99.90 \%$ to $99.99 \%$, respectively, using safe concentrations for cell lines. Shaheen et al. (2015) isolated EPS from L. bulgaricus OLL1073R-1 with a powerful immune-stimulating effect against CVB3. Furthermore, Biliavska et al. (2019) applied EPS extracted from Lactobacillus, Pediococcus, and Leuconostoc against human adenovirus type 5 and the reduction in viral infection reached $85 \%$ and when they added EPS after viral adsorption, the viral formation and release were completely suppressed.The high antiviral potential of EPS against CVB3 can be explained by many ways including the blocking of viral replication at all its stages such as attachment, penetration, replication of genetic materials and capsid, assembly, and viral release from the infected cells (Biliavska et al., 2019), also enhancing host immune system or degrade viral particles (Zhou et al., 2019). Furthermore, our EPS is a sulfated polysaccharide which is characterized by high potent effect against many viruses such as herpes simplex virus, hepatitis B virus, influenza virus, and human cytomegalovirus by inhibition of virus-cell attachment meaning the first step of viral infection (Kim et al., 2010). Finally, the type of EPS monosaccharide can affect the viral replication, where it was found that EPS contain glucose and mannose which had a good effect against coronavirus, so it must be focused on the role of glycolysis metabolism in viral activity (Harrison, 2020).

\section{Antioxidant activity by DPPH radical-scavenging method}

The antioxidant capacity of EPS was determined by DPPH as shown in Table 5. Both crude and partially purified EPS showed high antioxidant activity $(45.7 \%-62.1 \%)$ dependent on the sample concentration (40-240 $\mu \mathrm{g} / \mathrm{ml})$. The $\mathrm{IC}_{50}$ reached 127.9 and $128.7 \mu \mathrm{g} / \mathrm{ml}$ for crude and pure EPS, respectively. Abdel-Fattah et al. (2012) obtained a strong free radical-scavenging activity with levan produced from $B$. subtilis. Generally, the antioxidant property may have an important role in prevention of several diseases including cancer, heart disease, and immune system decline and act as an anti-inflammatory agent (Wang et al., 2017). So, LAB-EPS has unique properties, particularly the antitumor, antioxidant, and immunostimulant properties which can be applied as strong and safe drugs (Biliavska et al., 2019).

\section{CONCLUSION}

LAB bioproducts such as EPS can help to lead a healthy life. The current study was conducted to isolate and identify a
Table 5. Antioxidant activity of crude and partially purified EPS.

\begin{tabular}{cccc}
\hline Sample & Sample conc. $(\boldsymbol{\mu g})$ & DPPH $\%$ & $\mathbf{I C}_{50}(\boldsymbol{\mu g} / \mathbf{m l})$ \\
\hline Crude EPS & 40 & 45.7 & 127.9 \\
& 80 & 45.8 & \\
& 120 & 46.9 & \\
& 160 & 53.3 & \\
Pure EPS & 200 & 58.3 & \\
& 240 & 61.7 & \\
& 40 & 45.7 & 128.7 \\
& 80 & 45.8 & \\
& 120 & 46.6 & \\
& 160 & 53.6 & \\
& 200 & 58.8 & \\
& 240 & 62.1 & \\
\hline
\end{tabular}

probiotic strain that can produce EPS that has suitable properties for prevention/treatment of some diseases. The EPS extracted from $W$. paramesenteroides $\mathrm{MN} 2 \mathrm{C} 2$ was purified and identified and it was found to have qualified characters as an alternative biotherapeutic cancer drug with an antioxidant property which plays an important role in the treatment of tumor. Furthermore, our EPS could provide a good lead for the development of new antiviral drugs.

\section{ACKNOWLEDGMENTS}

The authors acknowledge the Chemistry of Natural and Microbial Products Department, National Research Center, for their support of this work and funding.

\section{AUTHOR'S CONTRIBUTION}

Mai Amer contributed to conceptualization, formal analysis, funding acquisition, methodology, resources, and writing the original draft. Eman Elgammal contributed to conceptualization, formal analysis, supervision, writing the original draft, review, and editing. Nagwa Atwa, Ahmed Eldiwany, Insaf Dawoud, and Ferial Rashad contributed to conceptualization, formal analysis, and supervision.

\section{CONFLICTS OF INTEREST}

The authors report no financial or any other conflicts of interest in this work.

\section{ETHICAL APPROVALS}

NOt applicable.

\section{PUBLISHER'S NOTE}

This journal remains neutral with regard to jurisdictional claims in published institutional affiliation. 


\section{REFERENCES}

Abdel-Fattah AM, Gamal-Eldeen AM, Helmy WA, Esawy MA. Antitumor and antioxidant activities of levan and its derivative from the isolate Bacillus subtilis NRC1aza. Carbohydr Polym, 2012; 89(2):314-22.

Adesulu-Dahunsi AT, Sanni AI, Jeyaram K. Rapid differentiation among Lactobacillus, Pediococcus and Weissella species from some Nigerian indigenous fermented foods. LWT, 2017; 77:39-44.

Awang N, Aziz ZA, Kamaludin NF, Chan KM. Cytotoxicity and mode of cell death induced by Triphenyltin (IV) compounds in vitro. J Biol Sci, 2014; 14:84-93.

Bajpai VK, Rather IA, Majumder R, Shukla S, Aeron A, Kim K, Kang SC, Dubey RC, Maheshwari DK, Lim J, Park YH. Exopolysaccharide and lactic acid bacteria: perception, functionality and prospects. Pharmacol, 2016; 11:1-23

Bedada TL, Feto TK, Awoke KS, Derra FA, Gebre SG, Sima WG, Negassi TY, Beyene Y. Microbiological and public health status of cooked meat and fish in Ethiopia. Open Microbiol J, 2020; 14:123-9.

Biliavska L, Pankivska Y, Povanitsa O, Zagorodnya S. Antiviral activity of exopolysaccharides produced by lactic acid bacteria of the Genera pediococcus, Leuconostoc and Lactobacillus against human adenovirus type 5. Medicina, 2019; 55:519.

Boual Z, Kemassi A, Khelil AOEH, Michaud P, El Hadj MDO. Partial characterization and hydrolysis procedure of water soluble polysaccharides extracted from onesaharian medicinal plant: Malvaaegyptiaca L. Int J Biosci Biochem Bioinforma, 2012; 2(2):100-3.

Boukhelata N, Taguett F, Kaci Y. Characterization of an extracellular polysaccharide produced by a Saharan bacterium Paenibacillus tarimensis REG 0201M. Ann Microbiol, 2019; 69:93-106.

Collins MD, Samelis J, Metaxopoulos J, Wallbanks S. Taxonomic studies on some leuconostoc-like organisms from fermented sausages: description of a new genus Weissella for the Leuconostoc paramesenteroides group of species. J Appl Bacteriol, 1993; 75:595-603.

Davis GHG. The classification of Lactobacilli from the human mouth. J Gen Microbiol, 1955; 13:481-93.

Dubey AK, Jeevaratnam K. Structural characterization and functional evaluation of an exopolysaccharide produced by Weissella confusa AJ53, an isolate from fermented uttapam batter supplemented with Piper betle L. leaves. Food Sci Biotechnol, 2015; 24(6):2117-24.

Haroun BM, Refaat BM, El-Menoufy HA, Amin HA. El-Waseif AA. Structure analysis and antitumor activity of the exopolysaccharide from probiotic Lactobacillus plantarum NRRL B- 4496 In vitro and In vivo. J Appl Sci Res, 2013; 9(1):425-34.

Harrison C. Corona virus puts drug repurposing on the fast track. Nat Biotechnol, 2020; 38:379-81.

Hayisama-ae W, Kantachote D, Bhongsuwan D, Nokkaew U, Chaiyasut C. A potential synbiotic beverage from fermented red seaweed (Gracilaria fisheri) using Lactobacillus plantarum DW12. Int Food Res J, 2014; 21:1789-96.

Holt JG, Krieg NR, Sneath PHA, Staley JT, Williams ST. Group 19. Regular nonsporing gram-positive rods. In: Bergey's manual of determinative bacteriology, 9th editionn, Williams and Wilkins, Baltimore, MD, pp 565-70, 1994.

Ismail B, Nampoothiri KM. Production, purification and structural characterization of an exopolysaccharide produced by a probiotic Lactobacillus plantarum MTCC 9510. ArchMicrobiol, 2010; 192(12):1049-57.

Jin H, Jeong Y, Yoo S, Johnston TV, Ku S, Ji GE. Isolation and characterization of high exopolysaccharide-producing Weissella confusa VP30 from young children's feces. Microb Cell Fact, 2019; 18:110.

Kanamarlapudi SLRK, Muddada S. Characterization of exopolysaccharide produced by Streptococcus thermophilus CC30. Biomed Res Int, 2017; 9:1-11.

Kim Y, Oh S, Yun HS, Oh S, Kim SH. Cell-bound exopolysaccharide from probiotic bacteria induces autophagic cell death of tumour cells. Lett Appl Microbiol, 2010; 51(2):123-30.
Kumar MA, Anandapandian KTK, Parthiban K. Production and characterization of exopolysaccharides (EPS) from biofilm forming marine bacterium. Braz Arch Biol Technol, 2011; 54(2):259-65.

Linares DM, Gómez C, Renes E, Fresno JM, Tornadijo ME, Ross RP, Stanton C. Lactic acid bacteria and bifidobacteria with potential to design natural biofunctional health-promoting. Dairy Foods Front Microbiol, 2017; 8:846.

Liu Z, Zhang Z, Qiu L, Zhang F, Xu X, Wei H, Tao X. Characterization and bioactivities of the exopolysaccharide from a probiotic strain of Lactobacillus plantarum WLPL04. J Dairy Sci, 2017; 100:6895-905.

Michalak I, Chojnacka K, Marycz K. Using ICP-OES and SEMEDX in biosorption studies. Microchim Acta, 2011; 172:65-74.

Mulaw G, Tessema TS, Muleta D, Tesfaye A. In vitro evaluation of probiotic properties of lactic acid bacteria isolated from some traditionally fermented Ethiopian food products. Int J Microbiol, 2019; 2019:1-11.

Nwodo UU, Green E, Okoh AI. Bacterial exopolysaccharides: functionality and prospects. Int J Mol Sci, 2012; 13:14002-15.

Osuntoki A, Korie I. Antioxidant activity of whey from milk fermented with Lactobacillus Species isolated from Nigerian fermented foods Fd. Technol Biotechnol, 2010; 48(4):505-11.

Pan D, Liu J, Zeng X, Liu L, Li H, Guo Y. Immunomodulatory activity of selenium exopolysaccharide produced by Lactococcus lactis subsp. lactis. Food Agric Immunol, 2015; 26(2):248-59.

Ren D, Jiao Y, Yang X, Yuan L, Guo J, Zhao Y. Antioxidant and antitumor effects of polysaccharides from the fungus Pleurotus abalones. Chem Biol Interact, 2015; 237:166-74.

Sange F, Nicklen S, Coulson AR. DNA sequencing with chainterminating inhibitors. Proc Natl Acad Sci U S A, 1977; 74:5463-7.

Schieber M, Chandel NS. ROS function in redox signaling and oxidative stress. Curr Biol, 2014; 24:R453-62.

Sepp E, Jugle K, Vasar M, Naaber P, Bjørksten B, Mikelsaar M. Intestinal microflora of Estonian and Swedish infants. Acta Pediatr, 1997; 86:956-61.

Shaheen M, Borsanyiova M, Mostafa S, Chawla-Sarkar M, Bopegamage S, El-esnawy N. In vitro effect of Dodonaea viscosa extracts on the replication of coxackievirus B3 (Nancy) and rotavirus (SA-11). J Microbiol Antimicrob Agents, 2015; 10(3):47-54.

Thabrew MI, Hughes RD, McFarlane IG. Screening of hepatoprotective plant components using a HepG2 cell cytotoxicity assay. J Pharm Pharmacol, 1997; 49:1132-5.

Trabelsi L, M'sakni NH, Ouada HB, Bacha H, Roudesli S. Partial characterization of extracellular polysaccharides produced by Cyanobacterium Arthrospira platensis. Biotechnol Bioprocess Eng, 2009; 14:27-31.

Tukenmez U, Aktas B, Aslim B, Yakut S. The relationship between the structural characteristics of lactobacilli-EPS and its ability to induce apoptosis in colon cancer cells in vitro. Sci Rep, 2019; 9:8268.

Wang J, Zhao X, Tian Z, Yang Y, Yang Z. Characterization of an exopolysaccharide produced by Lactobacillus plantarum YW11 isolated from Tibet Kefir. Carbohydr Polym, 2015; 125:16-25.

Wang X, Wang Y, Ren Z, Qian C, Li Y, Wang Q, Zhang Y, Zheng L, Jiang J, Yang C, Wang D, Zhang Y, Fan J, Wang Y. Protective effects of 20(S)-protopanaxtriol on viral myocarditis infected by coxsackievirus B3. Pathobiology, 2012; 79:285-9.

Wang Y, Wu Y, Wang Y, Xu H, Mei X, Yu D, Wang Y, Li W. Antioxidant properties of probiotic bacteria. Nutrients, 2017; 9:521.

Wu X, Jiang W, Lu J, Yu Y, Wu B. Analysis of the monosaccharide composition of water - soluble polysaccharides from Sargassum fusiforme by high performance liquid chromatography/electrospray ionization mass spectrometry. Food Chem, 2014; 145:976-83.

Yadav V, Prappulla SG, Jha A, Poonia A. A novel exopolysaccharide from probiotic Lactobacillus fermentum cfr 2195 production, purification and characterization. Biotechnol Bioinformatics Bioeng, 2011; 1:415-21. 
Yin JY, Nie SP, Zhou C, Wan Y, Xie MY. Chemical characteristics and antioxidant activities of polysaccharide purified from the seeds of Plantago. Asiatica. L. J Sci Food Agric, 2010; 90:210-7.

Zhou Y, Cui Y, Qu X. Exopolysaccharides of lactic acid bacteria: Structure, bioactivity and associations: a review. Carbohydr Polym, 2019; 207:317-32.

Zisu B, Shah NP. Effects of $\mathrm{pH}$, temperature, supplementation with whey protein concentrate, and adjunct cultures on the production of exopolysaccharides by Streptococcus thermophilus 1275. J Dairy Sci, 2003; $86: 3405-15$.
How to cite this article:

Amer MN, Elgammal EW, Atwa NA, Eldiwany AI, Dawoud IE, Rashad FM. Structure elucidation and in vitro biological evaluation of sulfated exopolysaccharide from lactic acid bacteria Weissella paramesenteroides MN2C2. J Appl Pharm Sci, 2021; 11(05):022-031. 